Histophysiology Laboratory (Prof. A. GHosh), Department of Zoology, University of Calcutta, Calcutta 19, India

\title{
Influence of Estrogen on the Histophysiology of the Uropygial Gland
}

\author{
B. R. MAITI
}

Received September 3, 1971

\begin{abstract}
Summary. The role of estrogen on the uropygial gland function was investigated following estradiol therapy to both sexes of adult pigeons and ovariectomy in pre-pubertal pigeons and ducks and in post-pubertal pigeons. Administration of estradiol in intact adult male pigeons elicited a regression of the uropygial gland. Parallel treatment of estradiol in female birds provoked a stimulation of this gland. Pre-pubertal spaying in pigeons and ducks (kept for 30 days) and post-pubertal ovarian ablation in pigeons (kept for 30 and 60 days) did not bring about any perceptible change in the uropygial gland. All these findings have been confirmed by gravimetric, histologic, karyodynamic and some cytochemical studies. It has been suggested that estrogen is not normally involved in the maintenance of the uropygial gland of female pigeons and adrenal androgen and/or other adrenocortical hormones replace estrogen in regulating the preen gland of females. The differential action of estradiol upon this gland has also been briefly discussed.
\end{abstract}

The role of estrogen on mammalian sebaceous glands has been studied extensively (Montagna and Ellis, 1963). Thus, Lawrence and Werthessen (1942) have reported that estrogen eliminated acne in human subjects while DE GRAAF (1942) observed a stimulation of the sebaceous glands in guinea-pigs. EBLING (1951) noted temporary hyperactivity of these glands in rats. Subsequently, the latter author found regression of the sebaceous glands and epidermis following estrus and estradiol implantation in rats. Hypertrophic changes in the sebaceous glands and the epidermis were also reported by EBLING (1954) during the proestrus. Stilbestrol caused a decrease of the surface lipids in the human (JARRETT, 1955). Spaying of adult rats had no effect on sebaceous gland size and mitotic activity, but following estradiol implantation in spayed or adrenalectomized or hypophysectomized adult rats these glands were suppressed (EBLING, 1957). A parallel depressing effect of estrogen has also been reported in mice (Bullough and Laurence, 1960), rats (Ebling, 1963) and human subjects (STRAuss and Pochi, 1963).

Influence of estrogen on the uropygial gland is rather incompletely understood. KAR (1947) has reported that diethylstilbestrol ( $0.3 \mathrm{mg}$ each daily for 42 days) did not elicit any change in the uropygial gland of intact cockerels except that the gland weight was increased. This author has also reported that stilbestrol treatment in castrate cockerels showed partial stimulation of the uropygial gland. KAR (1949) in another experiment showed an increase in the uropygial gland weight in juvenile female spotted munia, Lonchura punctulata due to estradiol administration (125 R.U. each daily for 25 days).

It is apparent that the role played by estrogen in maintaining the sebaceous type of glands (either in mammals or in birds) lacks clarity. Besides, the uropygial gland is a holocrine tissue where a constant influx of cell production and cell loss occur at a 
very high rate (MAITI, 1968) and these processes are positive cytological indices of the glandular activity (cf. PRICE, 1956). However, these were not considered in earlier investigations. Thus, the present investigation was undertaken to ascertain the role of estrogen on the uropygial gland following exogenous administration of estrogen in adult pigeons of both sexes and ovariectomy in prepubertal and postpubertal pigeons and ducks. The study was mainly based on body and gland weights, cytomorphology, karyodynamics and cytochemistry of lipids and basophilic substances of the uropygial gland.

\section{Materials and Methods}

One hundred eight pigeons (juvenile female, 14; adult male, 34 and adult female, 60 ) and thirteen female ducks were used. The experimental schedule is presented in Table 1. Hormonal injections were made into the breast muscle of the birds and the sites were alternated for successive treatments. Ovariectomy was done following surgical ablation and subsequent cauterization of the remaining follicles. The operation was performed upon the anesthetized birds (chloroform or ether). All the birds received aqueous colchicine subcutaneously in single dose $6 \mathrm{hrs}$ prior to autopsy. Injections were given at $4 \mathrm{a} . \mathrm{m}$. and the birds sacrificed at $10 \mathrm{a} . \mathrm{m}$. This schedule was followed in all the subsequent investigations to obtain a uniform mitotic picture (Maiti, 1968). Body weights were recorded at death. Following cervical dislocation, the uropygial gland was dissected out, cleaned, weighed on torsion balance and fixed in appropriate fixatives. For histological studies $6 \mu$ paraffin sections were stained by Heidenhain's azan and Masson's trichrome procedures. Karyodynamic investigations

Table 1. Experimental schedule

\begin{tabular}{|c|c|c|}
\hline Treatment & Species & \\
\hline \multicolumn{3}{|l|}{ A. Estradiol: } \\
\hline Control & Pigeon, 1 year old & $(\hat{o} 6$, 우 6$)$ \\
\hline $\begin{array}{l}\text { Estradiol benzoate (Progynon, Schering Corp., U.S.A.): } \\
0.5 \mathrm{mg} \text { each daily for } 10 \text { days }\end{array}$ & " & $(\hat{o} 6,+96)$ \\
\hline Estradiol benzoate: $2.5 \mathrm{mg}$ each daily for 10 days & " & $(\hat{o} 8$, ㅇ 8$)$ \\
\hline Control & "I & $($ o 6, 우 6$)$ \\
\hline Estradiol benzoate: $1 \mathrm{mg}$ each alternate day for 30 days & " & $(\hat{8} 8$, 8$)$ \\
\hline \multicolumn{3}{|l|}{ B. Spaying: } \\
\hline \multicolumn{3}{|l|}{ 1) Prepubertal } \\
\hline Sham-operated control & Pigeon, 1 month old & ( 96$)$ \\
\hline Spayed (duration: 30 days) & " & ( +8$)$ \\
\hline Sham-operated control & Duck, 1 month old & ( +5$)$ \\
\hline Spayed (duration: 30 days) & " & (요 8$)$ \\
\hline \multicolumn{3}{|l|}{ 2) Postpubertal } \\
\hline Sham-operated control & Pigeon, 1 year old & ( +5$)$ \\
\hline Spayed (duration: 30 days) & " & $(+8)$ \\
\hline Sham-operated control & " & (ㅇ 5$)$ \\
\hline Spayed (duration: 60 days) & " & ( 98$)$ \\
\hline
\end{tabular}




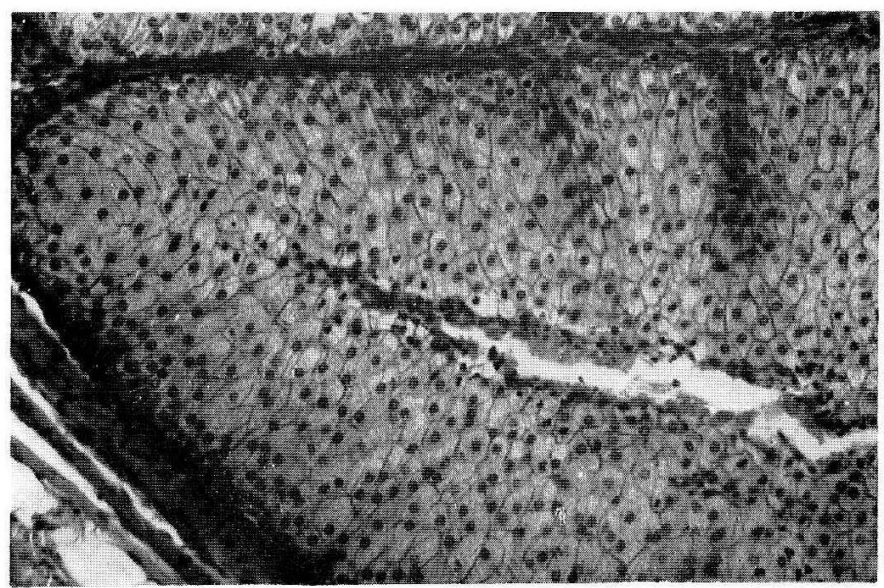

Fig. 1. Intact adult male

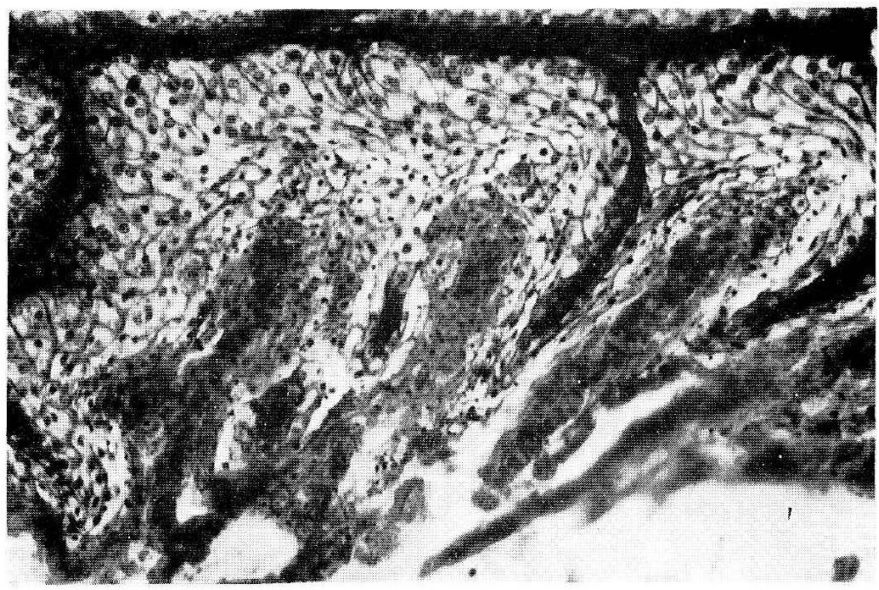

pigeon. A typical cytomorphological picture of the uropygial gland. $\times 135$

Fig. 2. Intact adult male pigeon plus estradiol (total: $15 \mathrm{mg} / \mathrm{bird}$ ). Note drastic cell loss followed by cellular extrusion, low epithelial height and hypoplasia in the regressed gland. $\times 135$

Fig. 3. Intact adult female pigeon plus estradiol (total: $15 \mathrm{mg} /$ bird). Glandular manifestations comparable to Figure 2 but in moderate form. $\times 135$

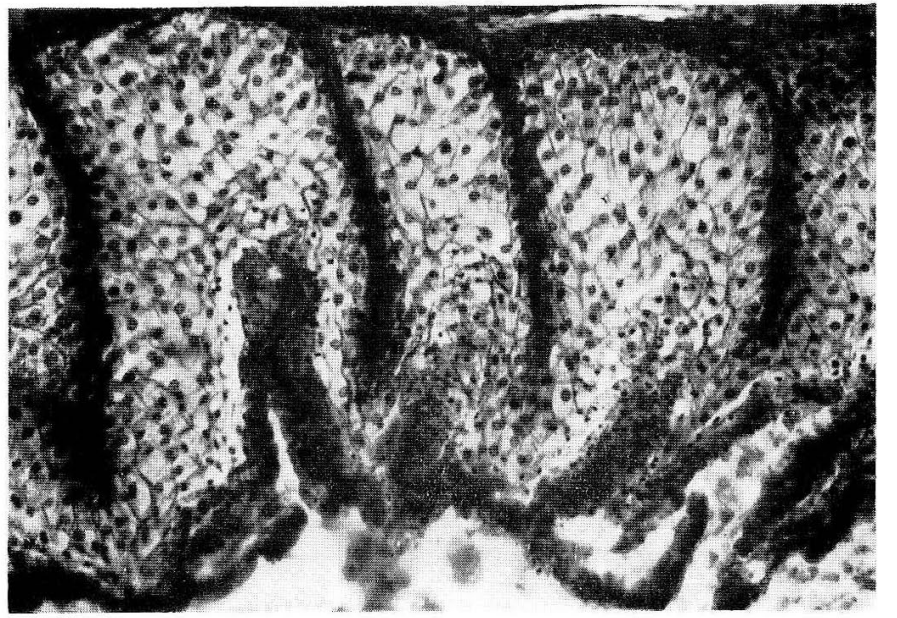


were performed on iron-alum haematoxylin and Masson's trichrome-stained paraffin sections. Method of differential cell count and calculation of daily mitotic rate and 'turnover' time of the uropygial gland have been described earlier (BERTALANFFY, 1957; Maiti, 1968). Paraffin sections were also employed for studying cytoplasmic basophilia (Montagna, Chase and Melaragno, 1951). Cytochemical study of lipids was performed on frozen sections of the gland (CAIN, 1947).

\section{Observations}

\section{A. Exogenous Estradiol Administration}

\section{a. In intact adult male pigeon}

\section{Control*}

The detailed histological description of the uropygial gland of pigeons has been mentioned earlier (Maiti and GHosh, 1969). However, the uropygial gland of the pigeon consists of branched alveoli having four cell types, arranged in centripetal order from the basement membrane to the center of the alveoli. These are flat basal cells, ill-differentiated cuboidal, differentiated polyheydral and lastly dark-stained pycnotic cells. The epithelial layers end in a lumen for secretory substances formed by the disintegration of fully differentiated cells. In general, the rate of cell production, cell differentiation and cell loss occurs moderately (Fig. 1).

The basophilic materials are more abundant in the basal cells than in the other cells of the uropygial gland of control birds.

Cytochemically detectable fatty acids are usually discernible in the basal and illdifferentiated cells while neutral fats are found in the differentiated cells and secretory materials of this gland.

\section{Acute treatment}

Low dosage: Estradiol administration $(0.5 \mathrm{mg} /$ bird daily for 10 days) in intact adult male pigeons did not cause any perceptible alteration in the uropygial gland (Table 2).

High dosage: Following high dosage of estradiol ( $2.5 \mathrm{mg} /$ bird daily for 10 days) the uropygial glands of the pigeons regressed evidently because of enhanced cell loss accompanied by low epithelial height and lower frequency of healthy cells (Table 2). No other significant changes were discernible.

\section{Chronic treatment}

Estradiol, when administered in moderate dosage and chronic form $(1.0 \mathrm{mg}$ each alternate day for 30 days) in male pigeons, caused a drastic regression of the uropygial gland compared to that of the high dosage recipient estrogenized birds. This was evident from a spectacular rise in cell loss followed by an overall increase in the cell extrusion process (Fig. 2). Further, the mitotic incidence became suppressed and the turnover time became slow (Table 2). The basophilic and the lipoidal materials were decreased in the estrogenized birds.

\footnotetext{
* This description is fairly valid for adult female and prepubertal pigeons.
} 


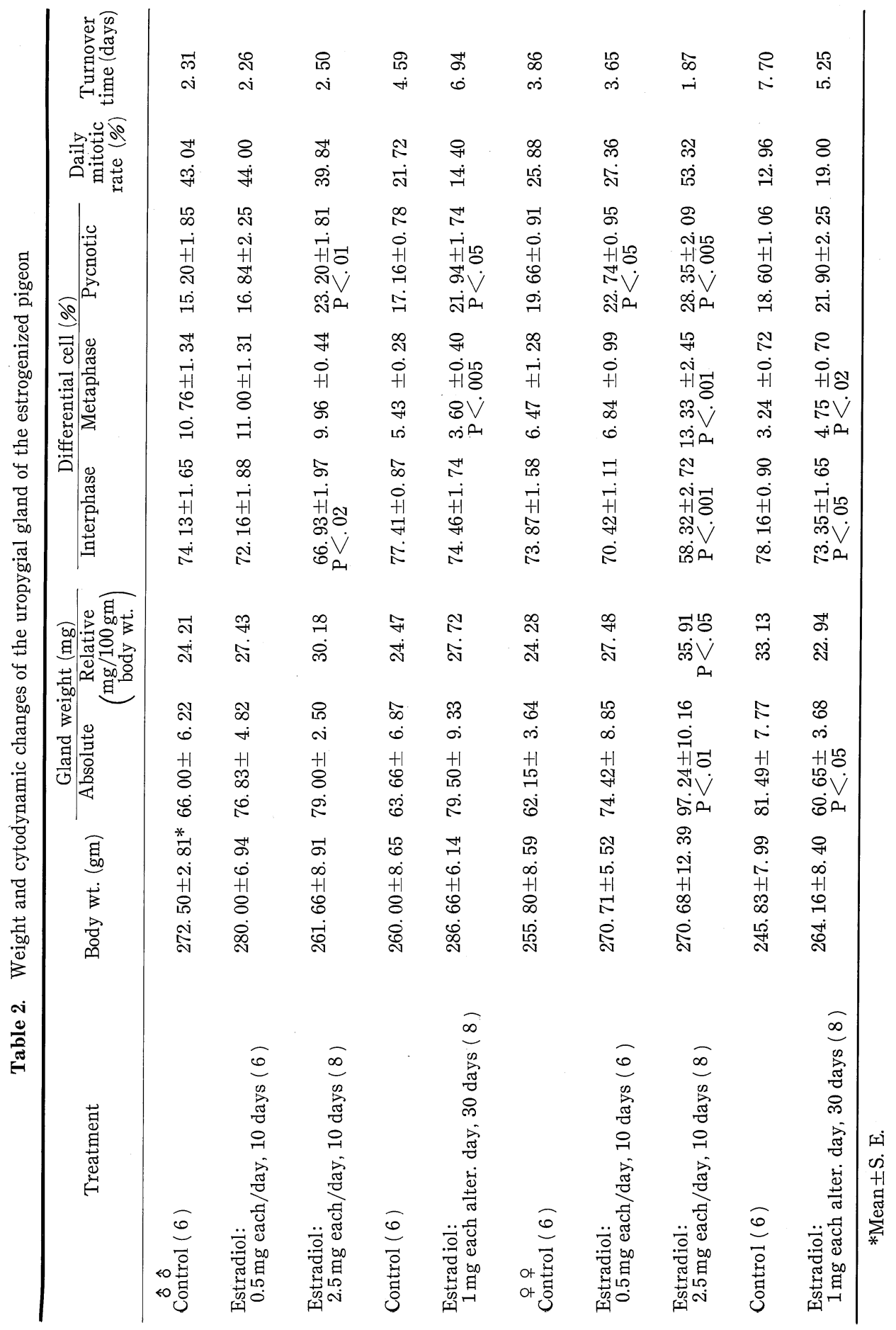




\section{b. In intact adult female birds}

\section{Acute treatment}

Low dosage: Female pigeons subjected to estradiol treatment (as in the male) failed to show any sharp alteration of the uropygial gland function (Table 2).

High dosage: Estradiol when administered in a high dosage like that of male birds resulted in a stimulation of the uropygial gland. This has been discernible from hyperplasia, faster turnover rate and increased cytochemically detectable basophilic and lipoidal substances of the gland (Table 2). Concomitantly, the rate of cell loss was accelerated to a moderate extent compared to that of the male birds which received a similar dosage of estradiol.

\section{Chronic treatment}

Parallel administration of estradiol in female pigeons to that in male birds provoked a moderate stimulation of the uropygial gland function as compared to that of the high dosage recipient females. The hyperactive manifestations were directed in the line as noted in the estrogenized-birds (Table 2). But the intensity of the results, particulary the cell loss, was lower than in the estrogenized male pigeons (Fig. 3).

\section{B. Spaying}

\section{a. Prepubertal female pigeons}

Bilateral ovariectomy in juvenile pigeons sacrificed after 30 days did not cause any conspicuous change in the activity of the uropygial gland except for weight increase (Table 3).

\section{b. Prepubertal female ducks}

The control uropygial gland of the male duckling has been described by GHosH and Maiti (1971). The uropygial gland of the female duckling does not vary significantly from that of the male. Cytomorphologically this gland is composed of simple tubular alveoli having similar types of cells as noted in pigeons except that the differentiated cells show large lipoidal droplets in ducklings. Cytochemically detectable basophilic and lipoidal materials from the uropygial gland of the ducklings are similar to those of pigeons.

The female ducklings 30 days after being subjected to surgical spaying showed an increase in the absolute weight of the uropygial gland. The secretory materials were profoundly increased and profusely found in the lumen of the central alveoli of the gland. Other changes were negligible (Table 3).

\section{c. Postpubertal female pigeons}

No sharp alteration was encountered in the uropygial gland of adult pigeons 30 and 60 days after total ovariectomy (Table 3 ).

\section{Discussion}

It is apparent from the present findings that unlike androgen, the role of estrogen on the uropygial gland is somewhat puzzling and it deserves some comments. Exogenous estradiol treatment in male pigeons provoked a regression of the uropygial 
Influence of Estrogen on the Uropygial Gland

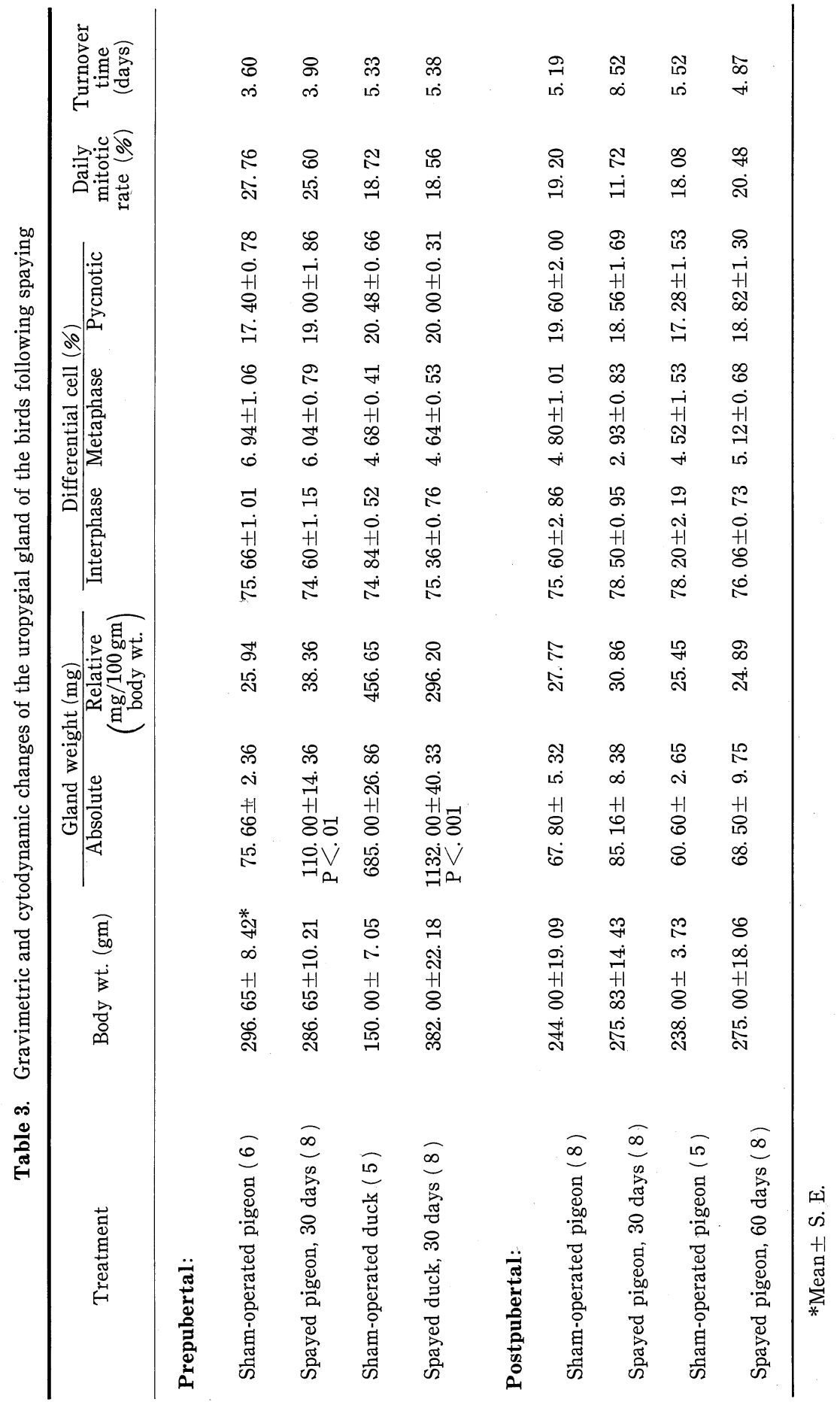


gland (Table 3). This atrophic manifestation was observed following chronic therapy of the hormone. The suppressing effect of estradiol was not marked in these birds when this hormone was administered for a relatively shorter period (Table 3). The differential behaviour of estradiol points out that the nature of hormonal administration is important for obtaining maximal effect. Our results, however, do not comply with those of $K_{A R}(1947)$ who observed an augmentation of the glandular function in intact and castrated cockerels following diethylstilbestrol treatments. Variation in the effect of natural and synthetic estrogens may very likely be related to the relative dosage schedules followed (NATHANSON, 1954). It is interesting to note that estradiol treatment in female pigeons resulted in a stimulation of the uropygial gland (Table 2). Estradiol was found to be effective in all the dosages and treatments followed in the present work except the low dosage which remained ineffective in these birds. This result may be comparable with that of $\mathrm{K}_{\mathrm{AR}}(1949)$ who has reported that estradiol treatment in the female spotted munia, Lonchura punctulata, resulted in a stimulation of the uropygial gland. Our data indicates that estradiol exerts its action upon the uropygial gland of both sexes of pigeons mainly by accelerating the cell breakdown or cell loss rate, because there was a profound cell loss (besides hyperplasia in females) in both the regressed and stimulated uropygial glands of male and female birds respectively due to estradiol treatment (Table 2). But the tempo of cell loss was found to be higher in males than that in females (Fig. 2, 3). However, a parallel cell loss induced by estrogen has been reported in mammalian sebaceous glands (EBLING, 1963). The latter author has further suggested that estrogen acts mainly by accelerating cell loss in mammalian sebaceous glands. Thus, our results on the uropygial gland corroborate with and further confirm the action of estrogen in mammalian sebaceous glands. Now a question may be raised as to the differential action of estrogen on male and female birds. It may be explicable in the light of the current research. It has been almost established that androgen stimulates and normally maintains the uropygial gland (GHosh and MaITI, 1971). Thus, in the male pigeons the regression of the uropygial gland induced by estradiol might have resulted from the suppression of testicular androgen (besides the participation of adrenal hormones). Our findings, however, comply with those of EBLING (1963) who observed a parallel action of this female sex hormone in mammalian sebaceous glands. But the situation is different in female birds because estradiol was found to stimulate the uropygial glands of these birds. Adrenal androgen has been known to maintain the mammalian sebaceous glands of females (STrauss and PocHI, 1963). Moreover, cortisone has been shown to stimulate the activity of the uropygial gland of the pigeon (MAITI and GHOSH, 1969). BHATTACHARYYA and others (1967) have also observed a hyperactive adrenal cortex in the female pigeons following estradiol administration. Taking the above facts into account, it may be presumed that participation of adrenal androgen and/or adrenal corticoids induced by estradiol might have been attributed to the stimulation of the uropygial gland in the estrogen recipient female pigeons. Refractoriness of the uropygial gland to spaying certainly points out that estrogen is not normally involved in the maintenance of the uropygial gland in female birds. One is apt to raise the question as to how the uropygial gland is maintained in female birds. It may be pertinent to cite the hormonal regulation of mammalian sebaceous glands in females. According to Ebling (1963) and Strauss and Pochi (1963), the sebaceous glands of 
females are normally maintained by adrenal androgen. Thus, the existence of a parallel relationship in the maintenance of the uropygial gland of female birds is not highly improbable. Besides adrenal androgen, probable participation of other adrenal corticoids in the maintenance of this gland in female birds is not very unlikely (MAITI and GHosh, 1969).

Thus, it may be concluded that estrogen, unlike androgen in male birds, does not normally maintain the uropygial gland of female birds, that adrenal androgen and other adrenocorticosteroids are possibly involved in the normal regulation of this gland of female birds, and that estrogen acts (suppresses or stimulates) mainly by accelerating the process of cell loss.

Acknowledgements. The author is deeply indebted to Dr. Asok GHosH for invaluable suggestions and criticism of this work. This investigation was supported by fellowship grants from the Council of Scientific and Industrial Research, Goverment of India and University of Calcutta. The gift of Progynon from Messrs. Schering Corporation, U. S. A., is heartily acknowledged.

\section{References}

Bertalanffy, F. D.: Mitotic activity and renewal rate of sebaceous glands cells in the rat. Anat. Rec. 129: 231-241 (1957).

Bhattacharyya, T. K., A. K. Sarkar, A. Ghosh and A. Ganguli: A comparative study on avian adrenocortical response to exogenous and endogenous corticotropin. J. exp. Zool. 165: 301-308 (1967).

Bullough, W. S. and E. B. Laurence: Experimental sebaceous gland suppression in the adult male mouse. J. invest. Dermatol. 35: 37-42 (1960).

Cain, A. J.: The use of nile blue in the examination of lipoids. Quart. J. microsc. Sci. 88: 383-392 (1947).

De Graaf, H. J.: Endocrine influences on sebaceous glands. Acta Brev. Neerland 12: 67-68 (1942).

Ebling, F. J.: Sebaceous glands. II Changes in the sebaceous glands following the implantation of estradiol benzoate in the female albino rat. J. Endocrinol. 7: 288-298 (1951).

-: Changes in the sebaceous glands and epidermis during the oestrous cycle of the albino rat. J. Endocrinol. 10: 147-154 (1954).

: The action of testosterone and oestradiol on the sebaceous glands and epidermis of the rat. J. Embryol. exp. Morphol. 5: 74-82 (1957).

-: Hormonal control of sebaceous gland in experimental animals. In: (ed. by) W. Montagna and R. Ellis: Advances in biology of skin. Vol. 4. Oxford, Pergamon Press, 1963. (p. 1-20).

Ghosh, A. and B. Maiti: Androgen control of uropygial gland. VI Europ. Conference of Comparative Endocrinologists, MontPellier, France, August, 1971.

Jarrett, A.: The effects of stilbestrol on the surface sebum and upon acne vulgaris. Brit. J. Dermatol. 67 : 165-179 (1955).

Kar, A. B.: The hormonal influence in the normal functioning of the uropygial gland in the fowl. Anat. Rec. 99: 75-89 (1947).

-: Stimulation of the uropygial gland in the female Indian spotted munia, Uroloncha punctulata (L), due to oestrogen treatment. Nature 164: 495-496 (1949).

Lawrence, $\mathbf{C}$. $\mathbf{H}$. and $\mathbf{N}$. T. Werthessen: Treatment of acne with orally administered estrogens. J. clin. Endocrinol. 2: 636-638 (1942). 
Maiti, B.: Cellular dynamics of the uropygial gland in the pigeon. Fol. biol. 16: 49-54 (1968).

Maiti, B. and A. Ghosh: Effect of cortisone on mitotic activity and cell loss in the uropygial gland of male pigeons. Acta anat. 74: 97-103 (1969).

Montagna, W. and R. A. Ellis: The sebaceous glands. In: (ed. by) W. Montagna and R. Ellis: Advances in biology of skin, Vol. 4. Oxford, Pergamon Press, 1963. (p. 272).

Montagna, W., H. B. Chase and H. P. Melaragno: Histology and cytochemistry of human skin. I. Metachromasia in the mons pubis. J. Nat. Cancer Inst. 12: 591-597 (1951).

Nathanson, I. T.: Endocrine management of neoplastic diseases. In: Glandular physiology and therapy. Philadelphia, J. B. Lippincott Co., 1954. (p. 464-476).

Price, D.: Dynamics of proliferating tissues. Chicago, University of Chicago Press, 1956.

Strauss, J. S. and P. E. Pochi: The human sebaceous gland: Its regulation by steroidal hormones and its use as an end organ for assaying androgenecity in vivo. Rec. Prog. Hormone Res. 19: $385-444$ (1963).

Dr. B. R. MAITI

Histophysiology Laboratory

Department of Zoology

University of Calcutta

35 Ballygunge Circular Road

Calcutta 19, India 